\title{
Thomas Aquinas
}

\section{on the Proportionate}

\section{Causes of Living Species}

\author{
BRIAN T. CARL \\ Center for Thomistic Studies \\ University of St. Thomas \\ carlbt@stthom.edu \\ ORCID: 0000-0003-1925-832X
}

\begin{abstract}
The principle of proportionate causality is often cited as a cause for concern that Thomistic metaphysics may be irreconcilable with a theory of biological evolution. St. Thomas does hold that for the generation of what he calls perfect animals, a generator of the same species is required. This study clarifies what the proportionate causes of generated organisms are for Thomas, examining his views about spontaneous generation, reproductive generation, and hybridization, while also articulating the roles of both the heavenly bodies and their separate movers as universal causes of generation. This study establishes that Thomas's assertion of the need for a univocal generator for perfect animals is grounded not in the principle of proportionate causality, but rather in physical and biological doctrines received from Aristotle and in a causal principle that seems reconcilable with biological evolution, namely, that a remote universal cause requires more mediating causes to produce more powerful effects.
\end{abstract}

Keywords: Thomas Aquinas; Aristotle; metaphysics; evolution; proportionate causality; spontaneous generation. 


\section{Introduction}

It is a frequently cited principle within the works of St. Thomas Aquinas that an effect cannot "exceed" its cause (SCG 1.67; ST 2-2.24.6 s.c.; De pot. 3.16 ad 8.), that an effect cannot be "more powerful" than its cause (In Sent. 4.23.2.2 qc. 1 ad 3; SCG 1.41, 3.120; ST 1.95.1, 1-2.66.1; De spir. creat. 11 ad $11)$, that an effect cannot be more perfect than its cause (ST 1-2.63.2 obj. 3). ${ }^{1}$ In numerous texts, Thomas also asserts that "nothing acts beyond its species" (In Sent. 2.18.2.3; De ver. 24.14; Quodl. 9.5.1; SCG 3.84; De pot. 3.9; ST 1-2.112.1), often indicating that this is so because no effect can be more powerful than its agent cause (In Sent. 2.18.2.3 obj. 3. Cf. De pot. 3.8 obj. 13; ST 1-2.112.1; Comp. theo. 1.93). As it is now often called, the principle of proportionate causality is also frequently expressed in the form that "nothing gives what it does not have." Such a principle is, understandably, a source for concerns about the irreconcilability of a theory of biological evolution with Thomistic philosophy. ${ }^{3}$

Like Aristotle, Thomas does in fact hold that there are some animal species whose members can only be generated through reproduction by already existing members of the same species: if this is so, then the emergence of such animals through any natural evolutionary process is impossible. That horses beget horses and human beings beget human

1 I offer my thanks to the Thomistic Evolution project, led by Nicanor Austriaco, O.P., with funding from the John Templeton Foundation, for opportunities to present and discuss earlier versions of this study and for support that made research for this project possible. I also owe my gratitude to David Cory, Brandon Zimmerman, Philip Neri Reese, O.P., Robert C. Koons, Daniel De Haan, Mariusz Tabaczek, O.P., Nicanor Austriaco, O.P., Richard Conrad, O.P., Raymond Hain, and Elliot Polsky for helpful comments and feedback.

2 This formulation only appears explicitly in Thomas's writings in objections. See e.g. In Sent. 4.15.2.6 qc. 1 obj. 2; ST 1-2.81.3 obj. 2, 3.64 .5 obj. 1. See first section below for discussion. Alternatively, as a character in a story by Ralph McInerny memorably puts it, "Nemo dat quod non got." See Ralph McInerny, The Prudence of the Flesh (St. Martin's Press: New York, 2006), 231.

3 Fr. Michael Chaberek has pointed to the principles that "no being can convey more act than it possesses," that "no effect can exceed the power of its cause" and that "the perfection of the cause cannot be lesser than the perfection of the effect" as incompatible with the evolutionary emergence of novel genera of living things. See Aquinas on Evolution (The Chartwell Press: 2017), 48; "Classical Metaphysics and Theistic Evolution: Why are They Incompatible?” Studia Gilsoniana 8.1 (2019): 56. 
beings might seem to be the most obvious application of the principle that "nothing gives what it does not have," that the actuality in an effect must be preceded by the same actuality in the cause: this is in fact the sort of example given by Aristotle in Metaphysics 9 in his discussion of the temporal priority of actuality in the universe, even if potentiality precedes actuality in the individual (Metaphysics 9.8).

As Aristotle's discussions of the generation of living substances (both in Metaphysics 7 and in his biological works) indicate, however, matters are somewhat more complicated, given his commitment to the claim that some living things are spontaneously generated, like flies from rotting flesh or oysters from slimy mud. It cannot be that in Aristotle or Thomas's mind the requirement for a generator of the same species, in cases like the horse or the human being, is simply a consequence of a general principle that "something cannot give what it does not have;" otherwise, spontaneous generation would seem to be ruled out. Matters are similarly complicated by Aristotle's discussion of another topic in the same texts, namely, animals that arise from hybridization, such as the mule, the offspring of a horse and a donkey. There is little hope of fully understanding Aristotle's assertion of the temporal priority of actuality or Thomas's principle that an effect cannot exceed its cause without an examination of their views about spontaneous generation and hybridization. I would propose that it is necessary to understand something of their biological and cosmological views in these cases, which are presumably consistent with their metaphysical principles, if one wishes to raise the question of how their principles might bear on the contemporary question of biological evolution.

This study will examine the notion of "proportionate causality" as discussed by Thomas, followed by an examination of what the proportionate causes are for Thomas (and for Aristotle, insofar as Thomas follows him) of spontaneously generated animals and of reproduced animals, including hybrids like the mule. This will allow us to clarify why Thomas holds that some animals can only arise through reproductive univocal generation. I will show that Thomas does not reach this conclusion merely by reasoning from something like the principle of proportionate causality. Rather, Thomas's 
reasons for asserting the need in some cases for a generator of the same species (a univocal generator) are grounded in physical and biological doctrines that he receives from Aristotle and in his understanding of the causal hierarchy in which changes in the sublunary depend upon the motions of the celestial bodies.

I will show that Thomas's understanding of the role of instrumental causality in univocal reproductive generation should undercut any use of the principle of proportionate causality to argue that biological evolution is irreconcilable with Thomas's metaphysical principles. In brief, Thomas does not in fact hold that any individual animal "has" its own nature in such a way that it is sufficient to "give" that nature to something else, for on his view an individual animal is an instrumental cause in the generation of another individual of the same species. I will also document that there is a general principle about the causal hierarchy that Thomas invokes in his discussions of the need for univocal generators-that more mediating causes are required for the constitution of what is more perfect-but I will argue that this principle is far from irreconcilable with biological evolution. I will conclude with some suggestions about implications for the debate about the reconcilability of Thomistic metaphysics with biological evolution.

\section{1. "Proportionate causality" in Thomas's thought}

Like the claim that "there is nothing in the intellect that is not first in the sense," the formulation that "nothing gives what it does not have" only explicitly appears in Thomas's writings in objections. As Therese Cory has recently shown, the formulation "there is nothing in the intellect that is not first in the sense" is in fact difficult to reconcile with many of the details of Thomas's understanding of human intellectual knowledge about incorporeal realities (Cory 2018). The truth to which Thomas is committed that is at issue in this well-known formula-the dependence of human intellectual cognition upon sense cognition-is better and more precisely expressed in other ways. I would suggest that in a similar way the formulation "nothing gives what it does not have" might easily mislead when one considers 
Thomas's views about animal generation and the requirement for a univocal generator in the case of what Thomas calls perfect animals.

When Thomas's recent interpreters who speak of the principle of proportionate causality offer an interpretation of what this principle means in practice in Thomas's thought, they say that the principle amounts to the claim that something's efficient cause must possess the form/perfection that it causes either by having that perfection formally (by actually having the same form in the same way), or by having it in a more eminent way, or by having it virtually, where to have it virtually is just to "have it" in such a way that it is able to cause it in something else (Feser 2017, 33).

Such a principle, so understood, will have some implications concerning something identified as an absolute first efficient cause: a first efficient cause of everything other than itself will have to possess all perfections at least virtually, and this in turn would be a reason for saying that an absolute first cause is superior to its effects, if it is also supposed, with Thomas, that virtual possession of some actuality can be a more perfect mode of possessing that actuality. ${ }^{4}$ But apart from this further claim, the principle that "nothing gives what it does not have," in its application to a given efficient cause, amounts only to the claim that an efficient cause must at least be able to cause whatever perfection it causes, even if its ability to cause that perfection is not due to its own formal possession of the perfection. It turns out to be a principle that doesn't tell us very much on its own.

Thomas does occasionally use the language of proportion between effects and causes, although typically not as a way of expressing the principle that an effect cannot exceed its cause. ${ }^{5}$ In several cases where Thomas speaks of a necessary "proportion" between effects and causes, he says (1) that per se effects are proportioned to per se causes, while per accidens effects are proportioned to per accidens causes (In Meta. 6.2.) and (2) that particular

4 ST 1.4.2: "Manifestum est enim quod effectus praeexistit virtute in causa agente, praeexistere autem in virtute causae agentis, non est praeexistere imperfectiori modo, sed perfectiori."

5 In one text he does offer as a principle that an effect must be proportionate to its cause: he argues that there must be something infinite about the object of supernatural hope, because it is caused by the infinite helping power of God. ST 2-2.17.2. 
effects are proportioned to particular causes, while universal effects are proportioned to universal causes (De ver. 2.5 ; De sub. sep. 10; SCG 2.21). ${ }^{6}$ As we will see below, the distinctions between per se and per accidens causes and between universal and particular causes are both centrally involved in Thomas's account of the generation of living things, along with the distinction between principal and instrumental causality. As noted above, Thomas does with some frequency assert that an effect cannot exceed or be more powerful than its cause, but he recognizes that such a restriction does not apply to the relationship between instrumental causes and their effects. ${ }^{7}$ He adds this same qualification to his claim that nothing acts outside of its species. ${ }^{8}$

\section{Thomas on novel species after the sixth day: on the mule}

Before turning to some of the details of Thomas's understanding of the proportionate causes of the species of living things, I want to make clear that consideration of such topics as spontaneous generation and hybridization will be directly relevant to thinking about the reconcilability of biological evolution with Thomistic metaphysics. In articulating his interpretation of the first book of Genesis in the Summa theologiae, Thomas considers the question of whether the work of creation is truly complete on the seventh day. The third objection in this article notes that many things of new species

6 In the last of these texts, St. Thomas also asserts that potential effects are proportioned to potential causes, while actual effects are proportioned to actual causes. These claims about the necessary proportions between effects and causes are ultimately indebted to Aristotle's discussion of the modes of causality in Physics 2.3 and to a claim made by Aristotle at the conclusion of this chapter. See In Phys. 2.6 \#197: "Et est, quod causis debent proportionaliter respondere effectus, ita quod generalibus causis generales effectus reddantur, et singularibus singulares; puta, si dicatur quod statuae causa est statuam faciens, et huius statuae hic statuam faciens. Et similiter causis in potentia respondent effectus in potentia, et causis in actu effectus in actu."

7 ST 3.79.2 ad 3: "Nihil autem prohibet causam instrumentalem producere potiorem effectum, ut ex supra dictis patet."

8 In Sent. 4.12.1.2 qc. 2 ad 2: "Ad secundum dicendum, quod propria virtute nihil agit ultra suam speciem: sed virtute alterius, cujus est instrumentum, potest agere ultra speciem suam, sicut serra agit ad formam scamni." 
appear even today, through spontaneous generation-this is the view of Aristotle. In Thomas's reply, he points both to spontaneous generation and hybridization as possible sources of novel species (ST 1.73.1 ad 3):

Nothing entirely new was afterwards [i.e., after the seventh day] made by God; rather, [all things] in some way preceded [as already made] in the works of the six days.[...] Also new species, if these appear, preexisted in certain active powers, just as animals generated from putrefaction are produced by the powers of the stars [i.e., the heavenly bodies] and of the elements, which [powers] they received at the beginning, if new species of such animals should also be produced. Certain animals of a new species sometimes also arise from the connection of animals of diverse species, as when from a donkey and a horse there is generated a mule, and this [species] too previously existed causally in the works of the six days.

The question might be raised, concerning this text, as to whether the mule is in fact a distinct species of animal, in Thomas's or Aristotle's mind. In some well-known remarks about mules in Metaphysics 7, Aristotle indicates that although the mule is neither a horse nor a donkey, it is nevertheless of the same genus as its parents, as a "beast of burden." Some interpreters fill in the gaps in a way that would deny that the mule is a genuine species, by suggesting that the mule is somehow an imperfect member of a genus but not a member of a genuine species. This is not what Aristotle says, however, and it would seem impossible to square with Aristotle's understanding of genera and species to suppose that some individual could exist which was merely of a genus without belonging to a species. ${ }^{9}$

About this point, in any event, Thomas asserts plainly in another text from the De potentia that the mule is of a species distinct from both the horse and the donkey, a species as it were in the middle between them ( $D e$ pot. 3.8 ad 16). Thomas's position in $S T 1.73 .1$ ad 3 is clear: there can be new species of living things that emerge after the work of the six days, so long as they can be said to be present in the active powers of things already created. That is, there must exist created things capable of causing their

$9 \quad$ See De anima 2.3. 
generation. Although this text concerning the seven days of creation is theological in character insofar as it expresses Thomas's interpretation of the creation narrative in Genesis 1, the view that novel species might arise from the active powers of already existent natural agents is strictly philosophical in character.

With respect to the mule, some interpreters also assume that Aristotle thinks that the mule is sterile simply because it is generated through hybridization and that its sterility is a consequence and sign of its imperfection or its failure to be of a genuine species. Aristotle discusses the mule at some length in De generatione animalium 2.7-8. We do in fact find in c. 8 an argument along the lines just suggested. In attempting to explain the sterility of mules, Aristotle suggests as what he calls an "abstract" and "general" proof of the sterility of mules that perhaps their sterility is due simply to the fact that the mule arises from the copulation of two animals different in species and is different in kind from each of its parents.

Immediately after presenting this apparent proof, however, Aristotle proceeds to say that "this account is too general and empty, since theories not based on the appropriate principles are empty, appearing to be connected with the facts without really being so.[...] The basis of this particular account is not true, for many animals produced from different species are fertile, as was said before." ${ }^{10}$ Aristotle has in fact listed numerous fertile hybrids of which he is aware earlier in the De generatione, and he has claimed that, as far as he knows, the mule alone is sterile among hybrid animals. Why then is this particular species sterile, on Aristotle's view? He proceeds to suggest that it has to do with the limited fecundity of the horse and the donkey. Each species typically gives birth to singletons; it often takes repeated mating for conception to occur; the donkey is of a colder nature than most quadrupeds; and the mare produces less menstrual blood than most female animals. That a colder nature makes for lower fertility is because Aristotle thinks that semen causes the generation of a new animal through vital heat, and he thinks that menstrual blood is the matter from which the new animal

10 De gen. anim. 2.8 748a8-13 [Barnes 1160]. 
is formed. Putting all of these factors together, Aristotle tells us that when a cross breeding contrary to nature "is added to the difficulty they have in producing a single one when united with their own species, the result of the cross breeding [...] will need nothing further to make it sterile." ${ }^{11}$ Aristotle's fascination with the mule is not because it is not of a genuine species; it is rather that there should exist any genuine species that is nevertheless by its nature sterile. But the explanation is to be found, he thinks, not in an abstract principle, but in the natures of the horse and the donkey from which the mule is descended.

\section{Reproduction and spontaneous generation in Aristotle}

The Aristotelian theory of animal generation-and Thomas's reception and understanding of that theory-cannot be properly understood apart from the Aristotelian cosmology and elemental theory. Aristotle conceives of the cosmos as a concentric series of incorruptible celestial spheres rotating eternally around the earth. The lowest of these spheres is that bearing the moon; everything below that sphere is made of the four simple, elemental bodies of earth, air, fire, and water, the simple bodies making up the sorts of physical substances that are subject to generation and corruption. The celestial spheres are, by contrast, incorruptible, and so must be not be composed of these simple bodies; the matter of the heavenly spheres is subject only to rotational locomotion and to no other sort of change.

The four elemental bodies in the sublunary are understood by Aristotle fundamentally in terms of certain active and passive qualities-heat, coldness, moisture, and dryness - and each of his elemental bodies combines a pair of these contrary qualities, as fire is the hot and dry, water is the cold and wet, and so on. The celestial spheres, and in particular that bearing the sun, are causes of heat in the sublunary: the sun heats the sublunary as its sphere rotates around the earth. The dependence of all substantial generation and corruption in the sublunary domain upon the rotation of the

11 De gen. anim. 2.8 748b16-19 [Barnes 1161]. 
heavenly spheres is grounded in the claim that the primary active quality in all sublunary substances is heat, which is caused in the sublunary by the sun. In what follows, I will briefly present some basic theses from Aristotle's understanding of animal generation that are appropriated by Thomas. ${ }^{12}$

On the Aristotelian theory of the generation of living things, it is through heat that matter is qualitatively disposed to the generation of the new living substance, just as it is also through heat that an individual animal digests and assimilates food into itself, through the hot blood that is concocted from food. In the case of reproduction among animals, the semen that comes from the father is itself concocted, purified blood (De gen. anim. 1.18 726a26, 1.19 726b2-12). The close relation between blood and semen in Aristotle's theory of reproduction is important to note: blood is that through which the animal ultimately assimilates nutrient into itself, growing and healing by generating its homogeneous parts, such as flesh and bone, in an organized fashion; semen is thoroughly concocted blood, endowed with a power similar to blood (a power to produce such things as flesh), but ordered to doing so in the conception of a new individual, from the matter provided by the female (De gen. anim. $2.4740 \mathrm{~b} 24$ ). As Thomas puts it, the semen has a "formative virtue" derived from the soul of the parent (ST 1.71 ad 1; De pot. 3.9 ad 16).

Aristotle compares the semen to the tool of a carpenter, endowed with the movements given by the carpenter, as if a tool could be endowed by a carpenter with a tendency to move in the way necessary to form a table, even once separated from the hands of the carpenter (De gen. anim. 1.22 730b9-24). But whereas the saw's movements are locomotions, semen acts through qualitative alteration, by heating in a structured way. ${ }^{13}$ And just as the saw does not become part of the table, so too Aristotle thinks

12 I am indebted to James Lennox, “Aristotle's Theory of Spontaneous Generation," in Aristotle's Philosophy of Biology (Cambridge: Cambridge University Press, 2001), 229-49, esp. 230-33; and to Daryn Lehoux, Creatures Born of Mud and Slime (Baltimore: Johns Hopkins University Press, 2017), 13-31.

13 This is not to preclude cases in which human artifice involves qualitative alteration or even produces a substantial change. See the latter part of section 6 below for bread-baking as an example of an artificially produced substantial change, on St. Thomas's view. 
of semen as an extrinsic agent that acts upon the passive matter-such as menstrual blood-supplied by the female. ${ }^{14}$ Just as many of the individual characteristics of a table would be due to the characteristics of the wood upon which the saw acts (perhaps even contrary to what the carpenter intends through the movements of his tools), so too many individual characteristics of the generated animal are due to and a likeness of the mother, due to her providing the proximate matter from which the animal is generated.

At this point, we should note that our understanding of sexual reproduction is quite different: the process of sexual reproduction is such that neither parent aims at a perfect copy of itself in all its individual characteristics, as the process is ordered per se towards some combination of traits of the parents or of the parents' own ancestors. On Aristotle's view, that the offspring should be anything but the spitting image of the father is always praeter naturam, apart from what the natural process of sexual reproduction intends. There is already more room for the notion of descent with modification on an understanding of sexual reproduction as a process that aims per se at a novel combination of traits.

\section{Instrumental causality in Thomas's account of generation}

It is because all heat in the sublunary depends upon the activity of the sun that all reproductive generation also depends ultimately upon the sun. As Aristotle observes in Physics 2.2-and this is an observation that is tremendously important for Thomas-“man and the sun generate a man." Thomas cites this observation frequently, and he takes it to mean that the sun and the individual animal are related to one another as (1) a universal, principal agent and (2) a particular, instrumental agent. Just as a carpenter might use a tool, an instrument, to produce some effect by a motion that the carpenter imparts to the instrument, so Thomas thinks that all generative activity by individual animals depends upon the heating action of the sun:

14 For the claim that the semen does not become part of the newly generated living thing, see De gen. anim. 2.3 737a12. 
the sun as it were uses the individual male animal as an instrument through which it produces new instances of the same species.

As noted above, in asserting the need for a proportion between causes and effects, Thomas distinguishes between universal causes and universal effects and particular causes and particular effects, asserting that universal effects must be proportioned to universal causes. Consider the following from c. 10 of Thomas's treatise De substantiis separatis:

A twofold cause is found of some nature or form: one which is per se and absolutely the cause of such a nature or form; but another which is the cause of this nature or form in this [individual]. Indeed the necessity of this distinction is clear, if one considers the causes of things that are generated. For when a horse is generated, the generating horse is the cause that the nature of a horse begins to exist in this [individual], but [the generating horse] is not the per se cause of the nature of horse. For in order for something to be the per se cause of some specific nature, it is necessary that it be its cause in all things having that species. Since therefore the generating horse has the same specific nature, it would need to be its own cause, which cannot be the case. It remains therefore that there must be, superior to all those things participating the nature of horse, a universal cause of the entire species. Such a cause the Platonists held to be a species separate from matter, in the manner that the principle of all artificial things is the form in art [i.e. the artist's knowledge], not existing in matter. But according to the opinion of Aristotle it is necessary to place this universal cause in some heavenly body: whence distinguishing these two causes, he said that man and the sun generate man.

In addition to the previously mentioned text from Physics 2.2, Thomas almost certainly has in mind here the discussion of the generation of living substances in Metaphysics 7, in which Aristotle rejects the theory of Platonic forms as causes of generation. In commenting on this part of Metaphysics 7, Thomas says that Aristotle intends to show, against Plato, that the natures and forms existing in individual sensible things need not be and could not be generated by forms existing outside of matter, but that they are generated “by forms which exist in matter" (In Meta. 7.6 \#1381). (Here I would recall Thomas's assertion that if novel species arise after the 
work of the six days, they do so from active powers found among already existent species.) Furthermore, Aristotle does not, on Thomas's view, do away with a single universal cause of generation, a universal per se cause of the generated nature: but he places this cause too within the material universe, in a heavenly body, the sun. As Thomas elsewhere puts it, endorsing what he takes to be Aristotle's view, "whatever causes generation in these lower [bodies] moves [its patient] to a species as the instrument of a heavenly body” (ST 1.115.3 ad 2., cf. SCG 3.69, ST 1.45.8 ad 3).

Here we come to a crucial point: it is not in fact Thomas's view that the individual generating animal is on its own a sufficient agent cause of the generation of a new animal within its own species, since the generating animal depends upon its being moved by a higher agency in order to cause a thing's nature. The individual animal does not have its nature, on its own, in such a manner that it is able to give that nature to something else; it has that nature in such a manner that it can be used instrumentally by a superior cause. It also bears repeating that on Thomas's construal of Aristotelian metaphysics, against Platonic metaphysics, one needs to place the active causes for the generation of natural substances within the material universe. I will return to this latter point at the end of this study.

\section{Spontaneous generation and the univocal generation of perfect animals}

Because the vital heat through which semen generates a new animal is itself ultimately from the sun, Aristotle and Thomas think that the phenomenon of spontaneous generation can be readily explained by the activity of heat present in non-living matter acting upon matter that happens to have become disposed in such a way that something living can be generated from it (such as putrefying flesh or slimy mud). There is some indeterminacy about what results from spontaneous generation, as what results depends upon how the matter happens to have been disposed, rather than upon the sort of structured heating by semen that aims at educing a specific form with certain individual traits. Animals arising by spontaneous generation arise 
by chance, by incidental (per accidens) causation, as the proximate cause is not acting for the sake of producing the specific effect.

Spontaneous generation (or generation by chance) involves per accidens causation, as the activity of the proximate causes is not for the sake of producing a specific result. Thomas explains in his Commentary on the Metaphysics 7.6 (In Meta. 7.6 \#1403):

Nothing prohibits some generation from being per se when referred to one cause, which is nevertheless per accidens and by chance when referred to another cause, as is clear in the very example given by the Philosopher. For when health follows from a rubbing, outside the intention of the one rubbing, the health [that results], if it be referred to the nature that regulates the body, is not per accidens, but is intended per se. But if [the health that results] be referred to the mind of the one rubbing, it will be per accidens and by chance. Similarly too the generation of an animal generated by putrefaction, if it be referred to particular causes, the inferior agents, will be found to be per accidens and by chance. For the heat that causes decay does not intend by natural appetite the generation of this or that animal that arises from putrefaction in the way that the power which is from the semen does intend the production in a certain species. But if [the generation from putrefaction] be referred to the heavenly power, which is the universal regulative power of generations and corruptions in these inferior [bodies], it is not per accidens, but intended, since it is of the intention [of the heavenly body] that there be educed into actuality all the forms which exist in the potency of matter.

The "proportionate causes" of spontaneously generated organisms include, for Thomas, both the incidental (per accidens) proximate cause and a per se remote, universal cause. In the case of generation through reproduction, the proximate cause acts as a per se cause whose causal activity is ordered towards a specific result, albeit still as a particular instrument of a universal, principal agency.

Aristotle in fact thinks that entirely new kinds of spontaneously generated animals may arise constantly, but he also holds that no spontaneously generated animal successfully reproduces in kind. On this point, we encounter a range of views in the later Peripatetic tradition. Thomas takes up 
this point in his commentary on Metaphysics 7, asserting (seemingly as an empirically observed fact) that there are species of plants that can be spontaneously generated and then go on to produce seed, reproducing in kind. This is a rather tame position compared to that of Avicenna, who (Thomas reports) asserts that any living species that can reproduce in kind-up to and including human beings - can also be produced, under the right material conditions, by spontaneous generation (In Meta. 7.6 \#1399-1401).

Thomas, by contrast, draws the line at what he calls perfect animals. Plants and imperfect animals may arise by spontaneous generation, but the generation of perfect animals requires the instrumental contribution made by the animal reproducing within its species (SCG 3.69; QDdA 5). Where Thomas indicates what he means by "perfect animals," he points to the organic complexity of higher animals in comparison to lower animals and plants, telling us that "perfect animals have a supreme diversity in their organs, but plants a minimal [diversity]" (SCG 2.72. Cf. ST 1.76.5 ad 3, $S T$ 1.76.8, $Q D d A 10$ ad 15). This is so because a perfect animal must have a wider range of powers, perhaps by having all of the senses (In Meta. 1.1 \#9) or more precisely by having the internal sense power of memory, in addition to imagination (In Meta. 1.1 \#14. Cf. ST 1.78.4).

It is essential to the notion of instrumental causality that an instrumental cause produces an effect that exceeds its own independent power, by virtue of its being moved by a principal agent, as the saw used by the carpenter produces a bed. But it is necessary to distinguish between those cases of instrumental causality in which the principal agent's own power is not augmented by the instrument and those cases in which the instrument does augment the power of the principal agent. All of the cases in which created agents act as instruments of divine agency are instances of the former sort, as a created instrumental cause never augments the power of the divine cause: God can produce immediately by His own power whatever He can also bring about through instrumental causes. But in many cases, a principal agent using an instrument is able to produce an effect that exceeds its power without the use of that instrument. Just as the tools of a carpenter also augment what the carpenter can accomplish through his 
hands, so on Thomas's view the heavenly body needs the contribution made by the reproducing animal in order to produce another instance of its species (In Meta. 7.6 \#1401).

Why should the instrumental contribution made by a univocal generator be necessary in the case of perfect animals, whose organic complexity surpasses plants and imperfect animals? Given his commitment to the view that animals like flies are spontaneously generated from rotting flesh, it is not that Thomas thinks that it is beyond the power of heat from the sun to educe the form of an animal with powers for sensation and locomotion. Thomas thinks, however, that the "structured" heating accomplished by semen is necessary in order to account for the formation of the more complex bodies of higher animals. By what principle does Thomas reach this conclusion? Thomas asserts that "the power of a heavenly body suffices for generating certain less perfect animals from disposed matter, for it is obvious that more [things] are required for the production of a perfect thing than for the production of an imperfect thing" (ST 1.91.2 ad 2. Cf. In Sent. 2.18.2.3 ad 5, De pot. 3.11 ad 12, In Meta. 7.6 \#1401). This principle that "more things" are required for the production of what is more perfect would seem to find some explanation in a text from De malo 16.9, which examines a question which we will discuss below, namely, whether a created immaterial substance (or more specifically, in De malo 16.9, a demon) can cause a qualitative or substantial change in a bodily thing.

In addressing this question in this text, Thomas asserts that generally, a more remote agent-he must mean a created agent rather than the divine agent-produces a weaker effect immediately, while needing a mediating agent to produce a more powerful effect (De malo 16.9). In the same text, he offers the following to illustrate his point:

For we see among sensible things that a weak effect is produced by a remote agent, but a strong effect requires a nearby agent; for something can be heated by fire, even if it is remote from the fire, but it cannot be ignited unless it is close to the fire, so that someone who wishes to ignite a thing that is remote from a fire in a lit furnace accomplishes this by means of a candle. And similarly 
the generation of perfect animals is caused by the heavenly bodies by means of proper active [causes], but the generation of imperfect animals [is caused by them] immediately.

Here I would highlight Thomas's explanation of why the heavenly body needs the instrumental contribution made by the univocal generator. The general principle employed is not a version of the principle of proportionate causality, but is instead a principle about the need for mediating instrumental causes in order for a created remote cause to produce a more powerful effect. This principle hardly seems irreconcilable with a theory of biological evolution.

\section{Separate substances as the living, intelligent movers of the heavenly spheres}

I have argued above that the instrumental causality of a univocal generator, on Thomas's account, should impact the way in which we understand the applicability of a principle of proportionate causality to the generation of living things. There is a serious objection with which I must contend, however, grounded in how Thomas himself replies to a series of objections motivated by something like the principle of proportionate causality.

In De pot. 3.11, Thomas considers the question of whether the sensitive or vegetative soul is transmitted through semen in the generation of an animal, a question to which he gives an affirmative answer (albeit with the qualification, consistent with what we have seen above, that the sensitive and vegetative soul are in the semen virtually rather than actually). The twelfth objection argues, contrary to Thomas's view, that the soul of a spontaneously generated animal must be created, because in this case there is no agent similar in species to the animal by which it might be produced; and so all the more, the objection insists, it must be that the souls of animals generated by semen must also be created. The thirteenth objection begins with a likely response (a sed dices) to the twelfth objection, followed by a sed contra (De pot. 3.11 obj. 13): 
But you will say that the sensitive soul is produced, in animals generated out of decay, by the power of a celestial body, just as [it is produced] in other [animals] by the formative power in semen. On the contrary, as Augustine says, a living substance is preeminent in comparison to every non-living substance. But a celestial body is not a living substance, since it is inanimate. Therefore a sensitive soul, which is a principle of life, cannot be produced by its power.

Here the counter-objection does appeal implicitly to something like the principle of proportionate causality. This is then followed in the fourteenth objection by another sed dices and sed contra (De pot. $3.11 \mathrm{obj} .14)$ :

But you will say that a heavenly body can be the cause of a sensible soul, insofar as it acts in the power of the intellectual substance which moves it. On the contrary, what is received in another is in it [i.e., the recipient] in the mode of the recipient and not in its own mode. If therefore the power of an intellectual substance is received in a non-living heavenly body, it will not be [received] there as a vital power which can be a principle of life.

In replying to this series of objections and counter-objections, Thomas begins by citing the principle we have already discussed, that "the more imperfect something is, the fewer are [the things] required for its constitution" (De pot. 3.11 ad 12). The power of a heavenly body is sufficient to produce the sensitive soul in an imperfect animal, but the heavenly body needs the contribution made by the reproducing animal in the case of perfect animals. Even though the heavenly body is not like in species to a spontaneously generated animal, "there is nevertheless a likeness insofar as the effect preexists virtually in [its] active cause" (De pot. 3.11 ad 12). So far, this is consistent with what we have said above.

In replying to the thirteenth objection and counter-objection, which had raised the concern that a heavenly body cannot be the cause of something living, because it is not itself living, Thomas replies by noting that "even if a heavenly body is not alive, it nevertheless acts in the power of the living substance by which it is moved, whether this be an angel or God; but a heavenly body is regarded as animated and alive according to the philoso- 
phers" (De pot. 3.11 ad 13). Here we do find Thomas replying to an objection motivated by something like the principle of proportionate causality by noting that although a heavenly body is not alive, the separate substance in whose power it acts is alive. The dialectical character of his reply is rather clear, given that he cites what he takes to be Aristotle's opinion-that the heavenly bodies are in fact animated-as an alternative reply that would satisfy the objector, and he does not commit here to whether it is the divine agent or a created separate substance that moves the heavenly bodies.

In any event, there is no question in Thomas's mind that the divine cause must be intelligent and living, and that God is known to be so on the basis of the presence of such pure perfections in creatures: Thomas is absolutely clear that all perfections must be found preeminently in the first cause. The objector is right to hold that what is living cannot be generated without the agency of something that is living; the question is whether the created agent possessing the proper power through which generation is caused must itself be living. St. Thomas's reply is that it suffices to answer the concern of the objector that some principal agent be living; but this has to be maintained along with the claim that the celestial body is an instrument without which a created separate substance could not generate a living thing.

The reply to the fourteenth objection and counter-objection is in this respect illuminating with regard to the causal relationship between a created separate mover and the heavenly bodies in the generation of living things:

The power of the living substance moving [the heavenly body] remains in the heavenly body and its motion not as a form having complete existence in a nature, but in the mode of an intention, just as the power of art is in the instrument of the artisan. ${ }^{15}$

15 De pot. 3.11 ad 14 [Marietti 75]: "Ad decimumquartum dicendum, quod virtus substantiae virtualis moventis relinquitur in corpore caelesti et motu eius, non sicut forma habens esse completum in natura, sed per modum intentionis, sicut virtus artis est in instrumento artificis." The Parma edition (1859) has spiritualis in place of virtualis, which would make better sense; I have opted to read virtualis here as vitalis. 
I would suggest that Thomas's comparison between the agency of a human artisan using an instrument to produce an artifact and the agency of a separate substance moving a heavenly body in order to generate living things is quite exact, particularly if we think about a case in which human artistry produces a substantial change through the use of the natural powers of some instrument.

Let us take the case of a baker producing bread through a fire in an oven. St. Thomas explicitly maintains that bread is a substance, that the form of bread is a substantial form. In replying to an objection (in his discussion of transubstantiation) against the status of bread as a substance appealing to the fact that bread is an artifact, St. Thomas replies that "nothing prohibits something being made by art whose form is not an accident but a substantial form," offering as a perhaps surprising example that frogs and snakes can be produced by art. ${ }^{16}$ So, on Thomas's view, in the case of the baking of bread, we have a substance that is produced by a human artisan, using the natural power of fire as an instrument (In Sent. 4.11.1.1 qc. 3 ad 3).

Although there is no natural process ordered per se towards the generation of bread, bread is produced per se by a baker, who uses the natural power of fire to heat the appropriate mixture of blended constituents in order to generate bread. Nothing would preclude bread being produced per accidens within nature: if wheat happened to be ground by falling stones into flour, which happened to be moistened by light rain into dough, which then happened to be heated by a brushfire (as improbable as the conjunction of

16 ST 3.75.6 ad 1. In addition, St. Thomas refers to the "substantial form of bread" in the body of this article. As for frogs and snakes generated by art, St. Thomas makes clear elsewhere that he has in the mind the art practiced by magicians, such as those of Pharaoh, and that this art involves the cooperation of demons. For texts concerning the generation of frogs by such an art, see SCG 3.104, ST 1.114.4 ad 2, ST 2-2.178.1 ad 2, De malo 16.9 ad 10. In any case, St. Thomas is clear that the magician and the demon make use of the powers of nature for the production of frogs, which St. Thomas includes among kinds that can be spontaneously generated (see ST 1.114.4 ad 2). For recent discussion of the status of bread as a substance in Thomas's thought, see Michael Rota, "Substance and Artifact in Thomas Aquinas," History of Philosophy Quarterly 21.3 (2004): 241-59; Christopher Brown, "Artifacts, Substances, and Transubstantiation: Solving a Puzzle for Aquinas's Views," The Thomist 71.1 (2007): 89-112; Anna Marmodoro and Ben Page, “"Aquinas on Forms, Substances, and Artifacts," Vivarium 54.1 (2016): 1-21. 
these events might be), then bread would be naturally produced per accidens. But the preparation of dough as matter and the efficient causality of fire are intentionally ordered by a human baker, who intends bread as an effect and is a per se cause of the generation of bread. This is an instance in which the instrument augments the power of the principal agent, as the baker needs the oven in order to make the bread.

The causal relationship between (i) the baker, (ii) the fire in the oven, and (iii) the bread produced is in most important respects equivalent to the causal relationship between (i) a created immaterial mover, (ii) the heavenly body, and (iii) a living thing spontaneously generated in the sublunary. Just as the baker cannot produce the form of bread except through fire, for St. Thomas created separate substances are unable to directly cause any formal transmutation of bodily substances; they are limited to causing changes of place. If a separate substance wishes to cause any transmutation of a bodily substance, it must use a mediating body, "just as a man can heat something through fire" (De malo 16.9). Just as the baker is the per se cause of the bread because he knows and intends the effect and employs fire as an instrument to bring about this effect, so the separate substance that causes the rotary locomotion of the heavenly sphere intends the generation of living things and employs the heavenly body as its instrument in the production of this effect. And just as, however improbable it might be, bread could in principle be produced in nature per accidens, so too I would suggest that in Thomas's cosmology if (per impossibile) there were any way for the heavens to undergo their circular rotation other than by the agency of separate movers, then the heavens would cause corruptions and generations, including spontaneous generations, in the sublunary.

That is, there is nothing in Thomas's account of the role of created separate substances as intelligent principal agents whose instruments are the heavenly bodies that would suggest that the natural power of the celestial body for causing generation in the sublunary in any way depends upon the intellectual or volitional acts of the separate substance, any more than the power of fire to generate bread from flour depends upon the baker's intellectual or volitional acts. The power of the fire and the power 
of the celestial body are only moved to produce bread and living things as per se effects by an intelligent principal agent, but in neither case does the intelligent principal agent give the power for generation to the instrument. Again, both the oven and the heavenly body augment the powers of their created principal agents.

If this account of the causal relationship between a created separate substance and an animal generated in the sublunary is correct, then St. Thomas's reply to the objection motivated by the principle of proportionate causality need not undercut what I have argued above. Even if St. Thomas is willing to grant that some principal agent-whether this be a created immaterial mover or God-must be living in order for something living to be generated, it nevertheless remains that the heavenly body, which is not itself living, is for St. Thomas the agent with the natural power able to educe the forms of spontaneously generated animals and able, through the instrumentality of animals within the sublunary, to bring about reproduction within a species.

\section{Concluding remarks}

As I have noted above, although he places restrictions on which living things can arise by chance from the activity of ambient vital heat, Thomas sees no difficulty in general about spontaneously produced organisms going on to reproduce in turn. As we have also seen in Thomas and Aristotle's discussion of the mule, there is no prohibition against two animals reproducing in such a way that what results from them is something different in species from either of the parents; and the sterility of the mule is not, for Aristotle, a consequence of its being a hybrid. It should be clear that such claims, taken together, might provide grounds for optimism about the reconcilability of Thomistic philosophy with biological evolution. Furthermore, as we have seen, the only general metaphysical principle that St. Thomas invokes in order to argue for the need for the instrumental contribution of a univocal generator is not the principle of proportionate causality, but instead the principle that a remote created universal cause needs the instrumental 
contribution of mediating instruments to produce more powerful effects. This principle seems reconcilable with evolution as well-although to articulate this reconciliation would require much further work.

If it is the case that metaphysical principles like the principle that effects cannot exceed their causes can only be understood in their concrete application in Aristotle and Thomas's thought in terms of some of the details of their biology and cosmology, then we should exercise due caution when bringing such principles to bear in thinking through problems posed by contemporary biology, chemistry, and physics. The preceding has been offered in the hope of giving some flesh and bones to the somewhat abstract metaphysical claims that the potential is preceded by the actual, that whatever is in the effect must first be virtually in the cause, as these claims were understood by Aristotle and Thomas. To understand these metaphysical principles as Aristotle and Thomas think about them requires that one think through the causal claims involved in their physics and biology. No principle in Aristotle or Thomas about "the perfect not arising from the imperfect" precludes the generation of new kinds of living things by chance. The requirement for univocal generators for higher animals is not a consequence of a metaphysical principle about proportionate causality; it is grounded more in physical and biological views about the difference between ambient vital heat and the structured heating performed by semen. If there were some disposed matter which could be acted upon in the necessary way by some physical agent other than sperm concocted from the blood of a male horse, there would be for Thomas no metaphysical prohibition against a horse arising by chance. Whether an account of reproduction grounded in biochemistry and genetics makes more room than the account grounded in the Aristotelian elemental theory for the per accidens generation of new species that go on to reproduce in kind is a question for the biologist: metaphysics does not preclude an affirmative answer.

My presentation of Thomas's understanding of the proportionate causes of living species invites questions about how one might adapt his views to contemporary cosmology and biology. For example, can we identify anything that plays something like the role played by the sun in his account, 
as a physical, universal, per se cause of generated living things? It is not my intention here to answer this question or the related question of whether Thomas's views can be reasonably adapted to fit an account which denies that there is any such physical universal cause. Given what I have tried to establish in this brief study, however, it should be clear that if we construct an account in which the role of the celestial bodies is removed and living things are identified as principal per se causes of their offspring, we have already significantly modified Thomas's views concerning the proportionate causes of living things.

Finally, I would emphasize that it is no accident that the matters of spontaneous generation and of the generation of the mule through hybridization are discussed by Aristotle in Metaphysics 7 and by Thomas's commentary on that work, in their argumentation against the need for Platonic separate forms as principles of generation. Their purpose is to show that causes which they identify in the natural world-the reproducing animals, even if they are of different species, the sun and the heat that it causes-are adequate for explaining the generation of all living things. In an Aristotelian cosmos, the active powers for the generation of living kinds are the powers of physical agents. In many recent discussions of how to possibly reconcile Thomistic metaphysics with biological evolution, contemporary authors have made direct recourse to the causality of the divine agent, who would be able to infuse the form of a new species into the first member of a new kind whenever the matter apt for that form has arisen by chance. Perhaps this is the metaphysical conclusion at which one needs to arrive; but if so, we will have left Aristotelian or Thomistic metaphysics behind on one of its central conclusions about natural substances. It is ironic, but understandable, that some have been led to do this, from a version of the "principle of proportionate causality" derived from the very discussion in which Aristotle and Thomas have argued against Plato. But perhaps we should, instead, be optimistic with Thomas that it pertains to the goodness of the divine to endow creation with the power to act as a genuine cause of anything moved or generated. 


\section{Abbreviations for the works of St. Thomas Aquinas}

Comp. theo. Compendium theologiae

De pot. Quaestiones disputatae de potentia Dei

De spir. creat. Quaestiones disputatae de spiritualibus creaturis

De sub. sep. De substantiis separatis

De ver. Quaestiones disputatae de veritate

In Meta. In duodecim libros Metaphysicorum Aristotelis expositio

In Phys. Commentaria in octo libros Physicorum Aristotelis

In Sent. $\quad$ Scriptum Super Sententiis Magistri Petri Lombardi

Quodl. Quaestiones quodlibetales

SCG Summa contra Gentiles

ST Summa theologiae

\section{References}

\section{Primary Sources}

Aquinas, Thomas. Sancti Thomae Aquinatis Opera omnia. Leonine edition. Rome: Ex Typographia Polyglotta S.C. de Propaganda Fide, 1882-.

Aquinas, Thomas. In duodecim libros Metaphysicorum Aristotelis expositio. Ed.

M. R. Cathala and R. M. Spiazzi. Marietti: Turin-Rome, 1971.

Aquinas, Thomas. Quaestiones disputatae. Vol. 2. Ed. M. Pession. Marietti: TurinRome, 1965.

Aquinas, Thomas. Scriptum super libros Sententiarum magistri Petri Lombardi. 4 vols.

1-2, ed. R.P. Mandonnet; 3-4, ed. M. F. Moos. Paris: Lethielleux, 1929-47.

Aquinas, Thomas. Summa contra Gentiles. Leonine Manual Edition. Rome: Leonine Commission, 1934.

Aristotle. The Complete Works of Aristotle. Ed. Jonathan Barnes. Princeton: Princeton University Press, 1984.

\section{Secondary Sources}

Brown, Christopher M, 2007. "Artifacts, Substances, and Transubstantiation: Solving a Puzzle for Aquinas's Views,” The Thomist 71.1: 89-112.

Chaberek, Michael. 2017. Aquinas on Evolution. Leicester: The Chartwell Press. 
Chaberek, Michael. 2019. "Classical Metaphysics and Theistic Evolution: Why are They Incompatible?” Studia Gilsoniana 8.1: 47-81.

Cory, Therese Scarpelli. 2018. "Is Anything in the Intellect that Was Not First in Sense? Empiricism and Knowledge of the Incorporeal in Aquinas," Oxford Studies in Medieval Philosophy 6: 100-143.

Feser, Ed. 2017. Five Proofs for the Existence of God. San Francisco: Ignatius Press.

Klubertanz, George P., 1941. "Causality and Evolution,” The Modern Schoolman 19.1: 11-14.

Marmodoro, Anna, and Page, Ben, 2016. “Aquinas on Forms, Substances, and Artifacts," Vivarium 54.1: 1-21.

McInerny, Ralph. 2006. The Prudence of the Flesh. New York: St. Martin's Press.

Lehoux, Daryn. 2017. Creatures Born of Mud and Slime. Baltimore: Johns Hopkins University Press.

Lennox, James. 2001. “Aristotle's Theory of Spontaneous Generation.” In Aristotle's Philosophy of Biology, 229-49. Cambridge: Cambridge University Press.

Rota, Michael, 2004. "Substance and Artifact in Thomas Aquinas," History of Philosophy Quarterly 21.3: 241-59. 